\title{
PLANEJAMENTO E GESTÃO ESTRATÉGICA MUNICIPAL: ESTUDO DE CASO DO CONTROLE INTERNO DA PREFEITURA MUNICIPAL DE CURITIBA
}

\author{
Planning and Municipal Strategic Management: Case Study of Internal Control of the \\ Municipal City Hall of Curitiba
}

\author{
Elisabeth Teixeira de Almeida Pereira \\ Instituto Municipal de Administração Pública \\ Mestrado em Gestão Urbana PUC-PR \\ elipereira@imap.curitiba.pr.gov.br
}

Denis Alcides Rezende

Programa de Mestrado e Doutorado em Gestão Urbana da PUC-PR denis.rezende@pucpr.br

Submissão: 26/11/2011

Aprovação: 25/01/2013

\section{Resumo}

Os controles internos estão relacionados com a gestão das prefeituras. O objetivo é analisar a efetividade do sistema de controle interno municipal e sua contribuição para o planejamento e gestão estratégica municipal. A metodologia da pesquisa enfatizou o estudo de caso único em Curitiba por meio de um protocolo de pesquisa. Os resultados aferidos demonstraram que a efetividade do sistema de controle interno municipal cabe à responsabilidade dos gestores no tratamento e disponibilização de informações estratégicas em tempo hábil atribuída à melhoria da qualidade da informação e da gestão para o alcance de seus resultados. Aferiu-se que a efetividade do sistema de indicadores para o planejamento e gestão estratégica permeia na dependência da definição e uso de indicadores estratégicos viáveis e equilibrados e na conscientização dos gestores em alimentarem tais sistemas. A conclusão reitera que o sistema de controle interno integrado à prática do planejamento no município pode corrigir distorções de gestão, inclusive social. Para tanto, é essencial que as informações disponibilizadas sejam efetivas e integradas entre os diferentes órgãos para assegurar a viabilização de estratégias propostas, objetivos a serem atingidos e ações a serem trabalhadas.

Palavras-chave: Controle Interno Municipal; Planejamento Municipal; Gestão Estratégica Municipal. 


\begin{abstract}
The internal controls are related to the management of the city halls. The objective is to analyze the effectiveness of the municipal internal control system and its contribution to the municipal planning and strategic management. The research methodology emphasized the case study in Curitiba structured through a research protocol. The measured results showed that the effectiveness of the municipal system of internal control is up to the responsibility of the managers in the treatment and provision of timely strategic information attributed to the improvement of the quality of the information and management for the reaching of their results. It was verified that the effectiveness of the indicator system for the planning and strategic depends on the dependency of the definition and use of feasible and balanced strategic indicators management and on the awareness of the managers of feeding such systems. The conclusion reiterates that the internal control system integrated to the planning in the municipality can correct management distortions, and social matters. For this reason, it is essential that the information provided be effective and integrated among the different organs to assure the feasibility of proposed strategies, objectives to be reached and actions to be performed.
\end{abstract}

Key-words: Internal Control; Municipal Planning; Municipal Strategic Management. 


\section{Introdução}

A partir da Constituição de 1988, novos desafios são apresentados à administração pública municipal no sentido de exigir dos governantes opções de serviços com qualidade para que possa responder de maneira adequada às demandas internas e externas. Nesse sentido, o controle assume papel importante ao impor limites à atuação do governo e orientar a melhor utilização dos recursos disponíveis de forma organizada e ponderada. Essa conscientização exige ações governamentais cada vez mais efetivas, principalmente após a Lei Responsabilidade Fiscal (LRF) que estabelece normas de finanças públicas voltadas para a responsabilidade na gestão fiscal da União, dos Estados, do Distrito Federal e dos Municípios. Essa obediência é essencial aos municípios, uma vez que a execução das ações governamentais está condicionada ao previsto no Plano Plurianual (PPA), Lei de Diretrizes Orçamentárias (LDO) e a Lei Orçamentária Anual (LOA). A adoção de controles internos e a sua organização estão relacionadas com a gestão das instituições governamentais, fazendo parte das Prefeituras como instrumentos estratégicos para a viabilização da sua missão.

A administração municipal ganha espaço frente aos desafios apontados pela melhoria da qualidade dos serviços prestados, bem como o intenso processo voltado ao controle político, econômico e social. Outro grande desafio permeia a busca por informações em tempo ágil e a utilização efetiva das informações para as estratégias do gestor público, alinhadas aos anseios dos cidadãos e a processos controlados e efetivos. A adaptação à nova realidade da administração municipal pressupõe ir além desses desafios que denotam contemplar, sobretudo, um conjunto de variáveis que poderão reconhecer transformações fundamentais na administração pública municipal. Como alternativa, o sistema de controle interno municipal pode assegurar a garantia dos gestores públicos e da própria gestão no sentido de verem alcançados seus objetivos e não serem vulnerados direitos subjetivos dos indivíduos nem as diretrizes da administração municipal.

O estudo do sistema de controle interno municipal denota, além do aprofundamento no conhecimento dos meios de controle, o reconhecimento e entendimento do processo de controle das ações governamentais municipais. Anteriormente à Constituição Federal de 1988, parte das decisões relativas à gestão estratégica municipal era tomada pelo respectivo Estado, de modo genérico e uniforme. Entretanto, tais decisões, pelo próprio afastamento e desconhecimento das realidades peculiares de cada município e do interesse local, mostravam-se incapazes de solucionar as necessidades existentes. $\mathrm{O}$ crescimento das cidades criou problemas econômicos complexos para seus gestores locais, como também gerou problemas de gestão, como dificuldades na tomada de decisões (LOPES, 1998). Além da constante preocupação com a economicidade das ações de governo, a constatação de que os gestores públicos necessitam de informações, porém essas informações muitas vezes são distorcidas e insuficientes, entregues tardiamente quando não são mais necessárias, ou ainda não existem ou estão numa apresentação ou formatação inadequada (CAVALHEIRO; FLORES, 2007). Sem informações, as organizações não conseguem tomar decisões adequadamente, nem interagir apropriadamente no ambiente em que se encontram, prejudicando, desta forma, o seu desempenho (PEROTTONI et al., 2001). A falta de uma visão comum da informação, dificulta a forma como as pessoas analisam, recolhem, organizam, processam, comunicam e utilizam a informação, o que significa ter dúvidas quanto à forma de obter resultados por meio da informação (REZENDE, 2008). Nesse sentido, é possível identificar problemas e dificuldades no processo de controle de gestão devido à existência de um nível de incerteza, o que faz com que as decisões e comportamentos assumam caráter pouco rotineiro e de difícil estruturação racional.

O gestor público enfrenta dificuldades. Ainda que atue com ética e seriedade, pode incorrer em ilegalidades por ausência do discernimento e capacitação necessários à boa gestão. Isto pode ocorrer, por exemplo, como resultado de ações isoladas e muitas vezes desconectadas de 
qualquer política pública ou do plano de governo. A prática de controles internos preventivos consiste em um dos caminhos fortemente calçados na busca de recursos humanos de alta qualidade e na internalização dos objetivos e valores organizacionais. Tais questões têm desafiado constantemente os municípios, requerendo atividades do governo local que devem ser pensadas para equilibrar essas relevantes temáticas. A administração pública municipal busca competência e efetividade dos seus gestores que devem se atualizar e agir por meio de instrumentos técnicos, modernos e práticos para o planejamento e gestão estratégica municipal (REZENDE, 2011).

O objetivo é analisar a efetividade do sistema de controle interno estratégico e sua contribuição para o planejamento e gestão estratégica municipal. Nesta dissertação, a ênfase dos controles estratégicos está na perspectiva da administração e não da contabilidade. $\mathrm{O}$ sistema de controle interno municipal está classificado em controles legais e controles estratégicos. Como controles legais: Plano Plurianual (PPA), Lei de Diretrizes Orçamentárias (LDO) e Lei Orçamentária Anual (LOA); e como controles estratégicos: controle administrativo estratégico e sistemas de informação e de indicadores estratégicos. Adota-se neste estudo, como conceito de efetividade, uma adaptação do conceito de Matias-Pereira (2007, p. 157) considerado "como a soma da eficiência e da eficácia, ou seja, quando os bens e serviços resultantes de determinada ação alcançam os resultados mais benéficos para a administração pública". A efetividade também pode ser entendida como "o somatório da eficiência (desempenho) e da eficácia (resultado) baseada na sua regularidade, praticidade, durabilidade e constância" (REZENDE, 2011). A administração envolve a interpretação de objetivos a fim de transformá-los em ação organizacional por meio do planejamento, da organização, da direção e do controle (REZENDE; CASTOR, 2006). A administração pública deve ser entendida como todo o sistema de governo, todo o conjunto de idéias, atitudes, normas processos, instituições e outras formas de conduta humana, que determinam a forma de distribuir e de exercer a autoridade política (MATIAS-PEREIRA, 2007).

Reitera-se como justificativa que a cobrança da população em ter um Estado mais democrático, a década de 80 foi responsável por gerar um processo de análise crítica do Estado. A Constituição Federal de 1988 atribuiu aos municípios um grau maior de autonomia que aquele anteriormente existente. A Constituição Federal descreve que a política de desenvolvimento local deve ser executada pelo poder público municipal, conforme diretrizes gerais fixadas em lei, e tem por objetivo ordenar o pleno desenvolvimento das funções sociais da cidade e garantir o bem-estar de seus munícipes. Estas questões podem acarretar uma série de consequências aos gestores públicos, diante de sua responsabilidade pelo correto e efetivo direcionamento das ações e recursos públicos, além do prejuízo à sociedade. Assim, a desobediência às exigências legais, seja por desvio de finalidade, seja por extrapolação dos recursos alocados, implica responsabilidade dos gestores públicos. A organização do controle interno é de responsabilidade do gestor público. Cabe a ele, em primeiro lugar, gerir os recursos da instituição que dirige, sem desperdícios e desvios. Em segundo lugar, deve manter as condições que demonstrem a prática da boa gestão, permitindo a verificação de que agiu com correção e competência. Quanto mais confiáveis, adequadas e rápidas forem as informações produzidas pelos instrumentos de controle, mais seguras serão as decisões tomadas (CASTRO, 2008, p. 63).

Por meio desse estudo, buscou-se contribuir para o aprofundamento da construção de conhecimento a respeito da efetividade do sistema de controle municipal e sua contribuição para o planejamento e gestão estratégica do município de Curitiba. No referido planejamento estão incluídas as temáticas financeiras e sociais, que também deve ser controladas e geridas. 


\section{FUNDAMENTAÇÃO TEÓRICA}

\subsection{Sistema de controle interno municipal}

A necessidade de se manter um sistema de controle interno vem sendo tratada com bastante interesse pela gestão municipal. Atualmente, sua utilização tornou-se imprescindível para o alcance das metas traçadas e para maior confiabilidade da gestão. Como conceito, controle é fazer algo que aconteça da forma como foi planejado. Consiste em um processo que oriente a atividade exercida para um fim previamente determinado. Está relacionado com a monitoração, acompanhamento e avaliação do processo de gestão estratégica visando melhorar, corrigir e garantir o funcionamento adequado de processos (REZENDE, 2011).

Attie (1998) salienta a importância do sistema de controle como um processo auxiliar de gestão, pois, quanto mais complexa a estrutura da organização maior é a necessidade de se ter controle sobre suas ações. Desse modo, ressalta-se que de acordo com Araújo, Arruda e Barreto (2008), para a gestão estratégica obter os resultados pretendidos é fundamental a implantação de controles internos adequados.

Dessa forma, torna-se importante esclarecer o estudo do suporte legal e dos conceitos desse sistema que para esta pesquisa estão relacionados a controles internos estratégicos de gestão, divididos em: controles legais PPA, LDO e LOA; controle administrativo estratégico; sistema de informação estratégico; e sistema de indicadores estratégico.

\subsubsection{Controles legais}

Do ponto de vista do suporte legal, a Constituição Federal de 88 segundo o Artigo 165, estabelece o sistema orçamentário federal regulado por três leis: a Lei do Plano Plurianual (PPA); a Lei de Diretrizes Orçamentária (LDO); e a Lei Orçamentária Anual (LOA).

A lei de Responsabilidade Fiscal reforçou a necessidade de articulação entre esses três documentos, na medida em que a execução das ações governamentais passa a estar condicionada à demonstração de sua compatibilidade com os instrumentos de planejamento: Plano Plurianual, Lei de Diretrizes Orçamentárias e Lei de Orçamento Anual (VAINER; ALBUQUERQUE; GARSON, 2005).

Sem perder a referência constitucional existente, a fundamentação teórica dos controles legais concentrou-se nos 3 instrumentos municipais de planejamento orçamentário.

\section{a. Controle legal - Plano Plurianual}

O Plano Plurianual, instrumento de planejamento municipal, estabelece objetivos, estratégias e ações municipais para as despesas de capital e de programas de duração continuada. Dele derivam a LDO e a LOA (REZENDE; CASTOR, 2006).

A vigência do PPA compreende quatro exercícios financeiros, iniciando-se no segundo ano de mandato de um Prefeito e terminando no primeiro ano de mandato do Prefeito subseqüente, evitando assim a descontinuidade das ações de governo. Ou seja, no primeiro ano de mandato o Prefeito que assume deverá cumprir o PPA do seu antecessor, assim como o Prefeito que o suceder deverá proceder da mesma forma (ANDRADE, et al., 2005).

O PPA é o plano de governo que expressa o planejamento de médio prazo. Evidencia os programas de trabalho do governo para um período de quatro anos especificados em diretrizes, objetivos e metas administrativas para as despesas de capital e outras delas decorrentes e para as relativas aos programas de duração continuada. As diretrizes do PPA são orientações, indicações e princípios estratégicos que nortearão as ações do governo municipal durante o período de sua vigência. Quanto ao sentido da palavra “objetivos", eles expressam os problemas diagnosticados que se pretende combater e superar e as demandas existentes que se espera atender, consistindo basicamente na definição dos programas de governo. Quanto às metas administrativas, refere-se aos resultados que serão atingidos por meio da execução dos programas e de suas respectivas ações governamentais, além de 
permitir o acompanhamento, a apuração e a avaliação dos custos e desses resultados possibilita demonstrar à sociedade se houve eficiência, eficácia e efetividade na aplicação dos recursos públicos (ANDRADE, et al.,2005). Ainda segundo estes autores e utilizando-se as definições da Portaria MOG n. 42/1999, torna-se mais evidente a definição dos objetivos para esse contexto: Art. 2. Para os efeitos da presente Portaria, entende-se por: Programa, o instrumento de organização da ação governamental visando à concretização dos objetivos pretendidos, sendo mensurado por indicadores estabelecidos no plano plurianual; Projeto, um instrumento de programação para alcançar o objetivo de um programa, envolvendo um conjunto de operações, limitadas no tempo, das quais resulta um produto que concorre para a expansão ou o aperfeiçoamento da ação de governo; Atividade, um instrumento de programação para alcançar o objetivo de um programa, envolvendo um conjunto de operações que se realizam de modo contínuo e permanente, das quais resulta um produto necessário à manutenção da ação de governo (ANDRADE, et al.,2005).

Portanto, para os referidos autores, os objetivos do PPA expressam a busca de resultados concretizados por meio da execução dos programas, que agregam as ações governamentais (projetos e atividades). Cada programa do PPA é mensurado por um ou vários indicadores, que quantifica a situação que se pretende modificar, visando à solução de um problema ou ao atendimento de determinada necessidade ou demanda da sociedade. Esse indicador pode ser considerado uma meta administrativa, pois parte de uma situação atual e projeta uma situação que se pretende atingir. As ações governamentais (projetos e atividades) são os instrumentos de programação que visam alcançar os objetivos dos programas onde é definida a quantidade dos produtos (bens ou serviços) que serão ofertados em cada ano de vigência do PPA. O PPA pode permitir o acompanhamento, apuração dos custos e avaliação dos resultados alcançados além da possibilidade em demonstrar se houve eficiência, eficácia e efetividade na aplicação dos recursos públicos utilizados.

A elaboração do PPA no Município cabe ao chefe do Executivo Municipal, em companhia do Poder Legislativo e da sociedade, traçar as diretrizes e os objetivos para os quatro anos de gestão, enquanto ao setor de Planejamento do Município, ou órgão equivalente, auxiliar o chefe do Executivo Municipal e os diversos setores da Administração na tradução das diretrizes e dos objetivos do governo municipal em programas, ações e metas, quantificadas física e financeiramente, de modo a viabilizar a elaboração, a execução e o controle do PPA, coordenando os trabalhos de elaboração dos planos setoriais, consolidando todas as propostas derivadas desses planos e formatando os projetos finais (ANDRADE et al., 2005).

\section{b. Controle legal - Lei de Diretrizes Orçamentária Anual}

A LDO é uma lei orçamentária anual, estabelece um conjunto de normas de forma e conteúdo para indicar as prioridades da administração municipal de cada exercício. Deve conter as metas priorizadas pela administração municipal (REZENDE; CASTOR, 2006). Na LDO são definidas as diretrizes que orientarão a Administração na elaboração da proposta orçamentária e na sua execução, sendo selecionadas dentre as diversas ações governamentais constantes no PPA aquelas que serão prioritárias durante a elaboração da LOA e da sua execução, compatibilizando-as com os recursos públicos arrecadados, (ANDRADE et al.,2005).

Portanto, na visão dos autores a LDO transcende a estimativa da receita e a fixação da despesa, que são objetivos da LOA, tendo como principal finalidade o planejamento e acompanhamento das finanças públicas, de modo a garantir o equilíbrio das contas públicas proporcionando assim, condições para que as demandas específicas da sociedade sejam priorizadas e realizadas.

\section{c. Controle legal - Lei Orçamentária Anual}

A proposta orçamentária é um documento que apresenta em termos monetários as receitas e as despesas públicas que o governo pretende realizar a um período de um exercício financeiro (de acordo com o art. Da Lei n. 4.320/1964, o exercício financeiro coincidirá com o ano civil. A Lei n. 810/1949 define ano civil, o qual segue o calendário), devendo ser elaborada pelo 
Poder Executivo e aprovada pelo Poder Legislativo, convertendo-se então na Lei Orçamentária Anual. É uma lei autorizativa e não impositiva, uma vez que o gestor de cada orçamento tem a faculdade de realizar ou não as despesas nela contidas (ANDRADE et al., 2005). A LOA proverá os recursos necessários para cada ação constante da LDO. Por meio dos seus planos operacionais, estabelece as receitas previstas e autoriza as despesas municipais. Explicita a política econômica e financeira e o programa de trabalho do governo municipal e define os mecanismos de flexibilidade que a prefeitura fica autorizada a utilizar. Requer para seu funcionamento os orçamentos-programa, que são documentos que evidenciam a política econômico-financeira e os programas de trabalho da gestão estratégica municipal, discriminando as despesas segundo sua natureza, dando ênfase aos fins ou objetivos, e não à forma como será gerado ou gasto o recurso. De modo a demonstrar em quê e para quê o governo gastará, e também quem será responsável pela execução de seus programas (CIDADES, 2002).

\subsubsection{Controle administrativo estratégico}

Os controles administrativos compreendem o plano de organização e todos os métodos e procedimentos relacionados com a eficiência operacional, bem como o respeito às políticas administrativas (CRC - SP 1996, p.52). A organização do controle administrativo estratégico é de responsabilidade da alta administração, deve estar voltado para a correção de eventuais desvios em relação aos parâmetros estabelecidos e prevalecer como instrumentos auxiliares de gestão (CERTO; PETER, 1993; SANTOS, 2006; CASTRO, 2008). Seu conteúdo tem caráter mais genérico e sintético se referindo aos seus aspectos globais da organização na implementação do seu planejamento estratégico (REZENDE, 2011).

O controle estratégico se concentra na monitoração e avaliação do processo da gestão estratégica para garantir o funcionamento integral do planejamento (CERTO; PETER, 1993; REZENDE; CASTOR, 2006). Em essência, é empreendido para garantir que todos os resultados planejados se materializem de fato (CERTO; PETER, 1993, p. 198).

\subsubsection{Sistema de informação estratégico}

Os sistemas de informação são o conjunto de partes que geram informações para os controles municipais. Têm como maior objetivo o apoio nos processos decisórios do município e da prefeitura. Os sistemas de informação estratégicos são sistemas que disponibilizam informações agrupadas e macrorrelacionadas com o meio ambiente interno e externo. Convencionalmente são direcionados para a alta administração da prefeitura que necessitam informações e que comparam as informações sintetizadas indispensáveis para apoiar a tomada de decisão (PEROTTONI, et al., 2001; REZENDE; CASTOR, 2006; STAIR; REYNOLDS, 2002; FURLAN; IVO; AMARAL, 1994, REZENDE, 2008).

Quanto mais confiáveis, adequadas e ágeis forem as informações produzidas pelas estruturas de controle, mais seguras serão as decisões tomadas (CASTRO, 2008, p. 63). Reconhecendo a importância dessas informações, a maioria das organizações estabelece sistemas de informações administrativas e sistemas de apoio às decisões administrativas. Uma vez estabelecidos, os sistemas de informação devem ser constantemente monitorados para garantir seu funcionamento apropriado. Sem tais informações, as atitudes tomadas para exercer o controle estratégico serão altamente subjetivas e terão pouca chance de melhorar consistentemente o desempenho organizacional (CERTO; PETER, 1993).

\subsubsection{Sistema de indicadores estratégico}

Os indicadores podem ser entendidos como uma das maneiras de se medir o desempenho de metas específicas. Eles resumem informações relevantes de um fenômeno particular ou um substituto de uma medida do comportamento de um sistema em termos de atributos relevantes, expressivos e perceptíveis. Podem ser dados que permitem quantificar, qualificar ou mensurar algum elemento desejado, devem contribuir com a medição, com o acompanhamento e com a avaliação das ações municipais, facilitando a sua compreensão e melhorando a qualidade de pesquisas ou de resultados. Na seleção dos indicadores é 
importante o entendimento do que se quer medir, das informações que se quer gerar e dos conhecimentos que se quer compartilhar. Os indicadores podem se constituir em sistemas de controles municipais, denominados de sistemas de indicadores (REZENDE; CASTOR, 2006; REZENDE, 2008).

Diversos são os sistemas de controles que a organização pode estabelecer para o acompanhamento e a avaliação do planejamento e gestão estratégica, eles armazenarão dados e disponibilizarão informações para que os controles municipais sejam elaborados (STAIR; REYNOLDS, 2002; FURLAN; IVO; AMARAL, 1994, REZENDE, 2011).

\subsection{Planejamento estratégico e gestão municipal}

A gestão municipal permite dar transparência ao uso de recursos públicos, uma vez que determina previamente os resultados a obter com o uso daqueles recursos, bem como os indicadores para mensurar o desempenho institucional (PACHECO, 1999; PFEIFFER, 2000). Após a Reforma do Estado e o advento da Lei de Responsabilidade Fiscal reforça a necessidade de considerar o planejamento como a ferramenta mais importante (PFEIFFER, 2000; ROSSI, et al., 2004). Planejamento é uma forma de aprendizado sobre as demandas e necessidades externas e sobre a capacidade de resposta da administração municipal (MOTTA, 2004, p.51). Para Rezende e Castor (2006) gestão municipal pode ser entendida como gestão da prefeitura e de seus órgãos, institutos, autarquias e secretarias. Está relacionada com o conjunto de recursos e instrumentos da administração aplicada na administração local, por meio de seus servidores municipais. No que se refere ao planejamento municipal, a gestão municipal enfatiza o planejamento estratégico municipal. O Planejamento Estratégico Municipal (PEM) é um processo dinâmico e interativo para determinação dos objetivos, estratégias e ações do município. É elaborado por meio de diferentes e complementares técnicas administrativas com o total envolvimento dos atores sociais, ou seja, munícipes, gestores locais e demais interessados na cidade. É formalizado para articular políticas federais, estaduais e municipais visando produzir resultados no município e gerar qualidade de vida adequada aos seus munícipes (REZENDE; CASTOR, 2006).

O PEM é um instrumento de gerenciamento, que como qualquer outro, tem um único propósito, tornar o gerenciamento de um município mais eficiente (PFEIFFER, 2000). A prática do planejamento nos municípios visa corrigir distorções administrativas, facilitar a gestão municipal, alterar condições indesejáveis para a comunidade local, remover empecilhos institucionais e assegurar a viabilização de estratégicas propostas, objetivos a serem atingidos e ações a serem trabalhadas. Como o planejamento é uma das funções clássicas da administração científica, é indispensável esse instrumento ao gestor municipal. Planejar a cidade é essencial, é o ponto de partida para uma gestão municipal efetiva frente à máquina pública, na qual a qualidade do planejamento ditará os rumos para uma boa ou má gestão, com reflexos diretos no bem-estar dos munícipes (ANDRADE, et al., 2005).

O processo de planejamento compreende as funções de planejamento, execução, controle e avaliação. O planejamento, segundo Matias-Pereira (2007, p. 78), "é um processo dinâmico de racionalização coordenada das opções, permitindo prever e avaliar cursos de ação alternativos e futuros, com vista na tomada de decisões mais adequadas e racionais." A execução consiste em organizar e distribuir tarefas de acordo com o plano e delegar autoridade para a execução. O controle é comparar as ações previstas determinada pelo plano com as realizadas e verificar se medidas corretivas foram tomadas em relação aos desvios. Após a avaliação dos resultados, um novo ciclo se inicia. Entender o planejamento como um processo implica em aceitar que não é uma atividade que se esgote na concepção de um plano, programa ou projeto. 


\section{METODOLOGIA DA PESQUISA}

Para fins de realização desta pesquisa, optou-se pelo estudo de caso da Prefeitura Municipal de Curitiba (PMC) como fonte de pesquisa da realidade envolvida. Estudo de caso para Yin (2001) é uma inquisição empírica que investiga um fenômeno contemporâneo dentro de um contexto na vida real. Em termos metodológicos, este artigo melhor se enquadra na linha de pesquisa exploratória, cujo objetivo é "proporcionar maior familiaridade com o problema, com vistas a torná-lo mais explícito," envolve levantamento bibliográfico a partir de material já publicado e entrevistas com pessoas que tiveram experiências práticas com o problema da pesquisa (GIL, 2002). O método de "estudo de caso único pode ser a base para explanações e generalizações significativas" (YIN, 2001). A pesquisa teve uma abordagem qualitativa onde a interpretação dos fenômenos e a atribuição dos significados são básicas no processo, não requerendo o uso de métodos e técnicas estatísticas e o ambiente natural é a fonte direta para a coleta de dados e o pesquisador é o instrumento-chave (SILVA; MENEZES, 2001).

\subsection{Fases e unidade de observação da pesquisa}

Para a realização do objetivo proposto, a pesquisa foi dividida em 4 fases: preparação da pesquisa, definição do instrumento para coleta de dados, realização da pesquisa e análise da coleta de dados das entrevistas. A preparação da pesquisa incluiu: a revisão da literatura onde se buscou fundamentação teórica por meio de levantamento bibliográfico de material já publicado; pesquisa documental sobre o sistema de controle interno municipal e planejamento e gestão municipal; e, elaboração do protocolo de pesquisa constituído por um construto denominado sistema de controle interno municipal. No construto foram identificadas variáveis e questões (critérios) a serem analisados, fundamentados nos autores pesquisados. Como instrumento de coleta de dados da pesquisa se elaborou um roteiro piloto de entrevista de natureza aberta com base no objetivo da pesquisa relacionado com as questões a serem analisadas em cada uma das variáveis elencadas no protocolo de pesquisa. A pesquisa foi aplicada por meio de gravação no ambiente de trabalho do entrevistado selecionado como forma de desenvolver linhas relevantes de questões, fornecendo alguma clarificação conceitual sobre o roteiro piloto elaborado. Por se tratar de entrevista de natureza aberta possibilita o uso da gravação permitiu a transcrição literal da entrevista.

Para análise dos dados coletados na entrevista, utilizou-se a abordagem qualitativa, onde o pesquisador analisou e interpretou os dados indutivamente sem uso de análise estatística, porém relacionado com as variáveis pesquisadas. Para Silva e Menezes (2001) na abordagem qualitativa, o pesquisador tende a analisar seus dados indutivamente. O processo e seu significado são os focos principais da abordagem. A interpretação dos fenômenos e a atribuição de significados são básicas para o processo.

A unidade de observação para a entrevista foi constituída pelos gestores públicos do nível estratégico que fazem parte do Grupo Funcional de Planejamento, Orçamento e Finanças da Prefeitura de Curitiba que tem por finalidade conferir mais objetividade e agilidade administrativa às ações da Prefeitura. As entrevistas foram realizadas com 1 presidente, 4 superintendentes, 2 diretores e 4 assessores.

\subsection{Protocolo de pesquisa}

O protocolo para o estudo de caso se constitui no documento que não apenas contém o instrumento, mas também define a conduta a ser adotada para sua aplicação. É uma das táticas principais para se aumentar a confiabilidade da pesquisa do estudo de caso (YIN, 2001; GIL, 2002). O delineamento da pesquisa determina o que deve ser pesquisado e o que deve ser analisado (ROESCHE, 1999, p.126). Para que a análise dos dados da pesquisa fosse viabilizada, foi necessário pesquisar, fundamentar e definir para cada uma das variáveis selecionadas, questões (critérios) para direcionar e interpretar seus resultados. Essas variáveis 
são parte fundamental do construto do protocolo da pesquisa. $\mathrm{O}$ construto foi denominado de sistema de controle interno municipal.

O construto foi desmembrado em variáveis fundamentadas em seus respectivos autores. As variáveis foram denominadas de: controle legal-PPA, controle legal-LDO, controle legalLOA, controle administrativo estratégico, sistema de informação estratégico e sistema de indicadores estratégico. Para cada uma das variáveis foram identificadas questões a serem analisadas na pesquisa. A pesquisa foi realizada no segundo semestre de 2010. 


\section{ANÁLISE DO SISTEMA DE CONTROLE INTERNO MUNICIPAL}

A gestão da municipal de Curitiba enfrenta variáveis bastante complexas numa cidade que abriga, um contingente populacional de 1.960.353 habitantes (CURITIBA, IPPUC, 2009). É a cidade pólo do conjunto de 26 municípios que formam a Região Metropolitana de Curitiba (RMC), com população de mais de 3 milhões de habitantes. A Prefeitura Municipal de Curitiba possui hoje, um quadro de recursos humanos que gira em torno de 35.000 servidores, distribuídos em uma estrutura de 21 órgãos da administração direta; 10 da administração indireta; além de 3 órgãos paraestatais. Está dividida territorialmente em 9 Administrações Regionais.

\subsection{Análise da variável controle legal - PPA}

Quanto à análise do controle legal PPA, estão contempladas as questões: atendimento às diretrizes e normas legais da PMC, efetividade do controle legal-PPA, integração e formas de contribuição do controle legal-PPA para o planejamento estratégico e gestão municipal.

Constatou-se que para o gestor entrevistado o controle legal-PPA atende o exigido pelas diretrizes e normas legais da PMC. Demonstra efetividade na análise do que foi ou não realizado e na identificação dos pontos positivos e negativos das ações. Quanto ao quesito integração com o planejamento estratégico e gestão municipal integra-se totalmente com Plano de Governo e o Plano Diretor desmembrado em planos setoriais.

No que tange a formas de contribuição do controle legal-PPA para o planejamento estratégico e gestão e municipal, auxilia o gestor municipal na visualização de médio prazo das diretrizes da Prefeitura: no detalhamento das ações previstas; revisão dos planos e processos de trabalho; e, na retomada de decisões.

\subsection{Análise da variável controle legal - LDO}

Quanto à análise do controle legal-LDO, estão contempladas as questões: atendimento às diretrizes e normas legais da PMC, efetividade do controle legal-LDO, integração e formas de contribuição do controle legal-LDO para planejamento estratégico e gestão municipal.

Observou-se que o controle legal-LDO atende o exigido pelas diretrizes e normas legais da PMC, demonstra efetividade pela execução da LOA e se integra com o planejamento estratégico gestão municipal ao desdobrar as grandes ações que serão realizadas com a previsão orçamentária relacionadas com o plano estratégico, tanto o Plano Diretor quanto os planos setoriais.

No que concerne a formas de contribuição do controle legal-LDO para o planejamento estratégico e gestão municipal, auxilia o gestor municipal na visualização do recurso disponível.

\subsection{Análise da variável controle legal - LOA}

Quanto à análise do controle legal-LOA, estão contempladas as questões: atendimento às diretrizes e normas legais da PMC, efetividade do controle legal-LOA, integração e formas de contribuição do controle legal-LOA para o planejamento estratégico e gestão municipal.

Verificou-se que o controle legal-LOA atende o exigido pelas diretrizes e normas legais da PMC, demonstra efetividade na execução e se integra com o planejamento estratégico e gestão municipal pelo desdobramento do Plano Diretor e Plano de Governo em programas e projetos detalhado em níveis de atividades e metas específicas para cada uma das ações devidas.

No que tange a formas de contribuição do controle legal-LOA para o planejamento estratégico e gestão municipal, como auxílio para a tomada de decisão dos gestores na priorização das ações a serem executadas, acompanhamento do desembolso e eventual correção de rumos das metas definidas. 


\subsection{Análise da variável controle administrativo estratégico}

Quanto à análise do controle administrativo estratégico, estão contempladas as questões: finalidade do controle administrativo estratégico utilizado pelos dirigentes municipais; efetividade do controle administrativo estratégico; integração e formas de contribuição do controle administrativo estratégico para o planejamento estratégico e gestão municipal.

Como finalidade do controle administrativo estratégico utilizado pelos dirigentes municipais, verificou-se a orientação do rumo a ser percorrido pelo gestor. Quanto à efetividade do controle administrativo, foi considerada efetiva pelas informações disponibilizadas pelos gestores. No quesito integração com o planejamento estratégico a gestão municipal se integra aos planos de ações dos órgãos pelo fornecimento de informações estratégicas efetivas.

Quanto às formas de contribuição do controle administrativo estratégico para o planejamento estratégico e gestão municipal, foi considerada a melhoria no planejamento e tomada de decisão dos gestores na definição das metas e diretrizes, e na revisão de quantidades e prazos.

\subsection{Análise da variável sistema de informação estratégico}

Quanto à análise do sistema de informação estratégico, estão contempladas as questões: efetividade do sistema de informação estratégico; integração e formas de contribuição do sistema de informação estratégico para o planejamento estratégico e a gestão municipal.

Atribuiu-se a efetividade do sistema de informação estratégico ao processo de feedback das informações utilizadas. Quanto à integração com o planejamento estratégico e gestão municipal, foi considerado que se integra por meio dos sistemas corporativos da Prefeitura.

No que concerne a formas de contribuição do sistema de informação estratégico para o planejamento estratégico e gestão municipal, foi atribuída à análise do que está sendo realizado e na prestação de contas das ações municipais.

\subsection{Análise da variável sistema de indicadores estratégico}

Quanto à análise do sistema de indicadores estratégico, estão contempladas as questões: efetividade do sistema de indicadores estratégico; integração e formas de contribuição do sistema de indicadores estratégico para o planejamento estratégico e a gestão municipal.

A efetividade do sistema de indicadores estratégico é demonstrada pela utilização de indicadores ou metas estabelecidas que permitam verificar o resultado do que foi programado. No quesito integração com o planejamento estratégico e gestão municipal, foi citado o sistema de acompanhamento e execução do plano de governo (PLANGOV) onde estão contemplados todos os indicadores estratégicos da gestão e do planejamento que incluem os indicadores do PPA e LOA.

No que tange as formas de contribuição do sistema de indicadores estratégico, foram citadas: norte para o alcance da administração e o grau de coerência dos indicadores que possibilita a medição dos resultados.

\section{ANÁLISE COMPARATIVA DA EFETIVIDADE DO SISTEMA}

No que concerne à efetividade do sistema de controle interno municipal, com base nos percentuais atribuídos à efetividade dos controles legais PPA, LDO e LOA, controle administrativo estratégico e sistemas de informação e indicadores estratégicos, criou-se um quadro comparativo da efetividade do sistema de controle interno, demonstrado na Tabela 1. 
Tabela 1 - Comparativo da efetividade do sistema de controle interno municipal

\begin{tabular}{l|l|l|l}
\hline $\begin{array}{l}\text { Efetividade do Sistema de } \\
\text { controle interno municipal }\end{array}$ & $\begin{array}{l}\text { Efetiva } \\
(\boldsymbol{\%})\end{array}$ & $\begin{array}{l}\text { Parcialmente } \\
\text { efetiva } \\
(\boldsymbol{\%})\end{array}$ & $\begin{array}{l}\text { Não } \\
\text { respondeu } \\
(\boldsymbol{\%})\end{array}$ \\
\hline Controle legal - PPA & 55 & 36 & 9 \\
\hline Controle legal - LDO & 91 & 0 & 9 \\
\hline $\begin{array}{l}\text { Controle legal - LOA administrativo } \\
\text { entrole }\end{array}$ & 73 & 18 & 9 \\
\hline $\begin{array}{l}\text { Sistema de informação } \\
\text { estratégico }\end{array}$ & 55 & 9 & 0 \\
\hline $\begin{array}{l}\text { Sistema de indicadores } \\
\text { estratégico }\end{array}$ & 55 & 45 & 0 \\
\hline
\end{tabular}

Fonte: os autores.

No que tange à análise comparativa do sistema de controle interno municipal, aferiu-se que a efetividade dos controles legais PPA, LDO e LOA é demonstrada pelo mesmo nível de detalhamento das 3 leis orçamentárias, ou seja, qualquer alteração em um dos instrumentos impacta na readequação dos demais (ANDRADE et al., 2005). Por outro lado e não menos importante, a efetividade parcial dos controles foi atribuída por 4 gestores entrevistados a este mesmo detalhamento que engessa o planejamento de longo prazo descaracterizando a essência do PPA adotado anteriormente pela prefeitura que não exigia este detalhamento.

A LDO, por ser de natureza técnica, demonstra efetividade na realização da LOA; como instrumento de diretriz permite à PMC uma reflexão do orçamento e visualização do valor orçado, traduzida no cronograma para execução de metas para a realização de ações governamentais (PESSINI JÚNIOR, 2007).

Para LOA, a efetividade foi atribuída em virtude de ser uma lei autorizativa, permitir flexibilização no remanejamento das ações, ou seja, define os mecanismos de flexibilidade que a prefeitura fica autorizada a utilizar (REZENDE; CASTOR, 2006). Atualmente na prefeitura, está limitada em $20 \%$ de alterações para possibilitar a acomodação de estratégias emergenciais com menor impacto de remanejamento e de custos, fato este considerado como parcialmente efetiva por 2 gestores entrevistados que consideraram que este mesmo limite pode comprometer o cumprimento daquilo que havia sido programado anteriormente, ou seja, reprogramada para o próximo exercício.

Atribuiu-se a efetividade do controle administrativo estratégico, à transparência dos resultados no momento da publicização; à alimentação de informações estratégicas efetivas que são de responsabilidade dos gestores; e ao detalhamento dos contratos de gestão que são apoiados, monitorados e avaliados pela Unidade de Gestão da prefeitura. Cabe ao gestor público gerir os recursos da instituição que dirige reforçando os mecanismos de controle e transparência e verificar se agiu com correção e competência (SILVA; AMORIM; SILVA, 2004; CASTRO, 2008). Quanto à efetividade parcial, atribuiu-se ao fato dos objetivos de governo estarem relacionados ao resultado do quanto se utilizou do orçamento.

No que tange ao sistema de informação estratégico, para 6 gestores entrevistados foi atribuída a possibilidade de a informação estratégica gerada permitir análise da informação organizada, facilitar a tomada de decisão e realinhar a estratégia, ou seja, os sistemas de informação estratégicos permitem a otimização interna das informações ao possibilitar aos gestores estratégicos o acompanhamento, avaliação e revisão de suas ações; e à transparência dos resultados como exemplo o ícone "Curitiba Aberta", demonstrado no site da prefeitura, que disponibiliza relatórios de controle orçamentários e administrativos para prestação de contas. É imprescindível que o gestor público disponha de informações estratégicas 
adequadas, precisas, oportunas e personalizadas, sempre relacionadas com o meio ambiente interno ou externo da organização pública (FURLAN; IVO; AMARAL, 1994; GRAHAM JÚNIOR; HAYS, 1994; FREITAS et al., 1997; REZENDE; CASTOR, 2006; REZENDE, 2008).

Quanto à efetividade parcial do sistema de informações atribuída por 5 gestores entrevistados foi em virtude dos poucos resultados visualizados pela natureza primária dos dados disponibilizados nas informações e pela necessidade constante de atualização das informações serem trabalhadas dentro dos órgãos como fonte de informação para a gestão, fato considerado como fator crítico de sucesso dos sistemas.

E finalmente, a efetividade do sistema de indicadores estratégico é demonstrada pelo estabelecimento de 90 indicadores viáveis para o alcance dos resultados que retratam a forma de gestão, ou seja, pelo conjunto de indicadores consolidados que de fato trazem resultados e pelo sistema disponibilizar informações em tempo real. Portanto, a definição de indicadores deve estar associada às estratégias e metas da organização, visando o monitoramento contínuo do desempenho organizacional (RODRIGUEZ, 2001; REZENDE, 2008). Atribuiu-se a parcial efetividade do sistema de indicadores estratégicos em virtude dos indicadores sofrerem alterações de curto prazo e serem avaliados mais pela efetividade das informações; se realmente atendem o que é necessário; e, necessidade de conscientização dos gestores em alimentar o sistema.

Aferiu-se que a efetividade do sistema de indicadores para o planejamento e gestão estratégica permeia na dependência da definição e uso de indicadores estratégicos viáveis e equilibrados e na conscientização dos gestores em alimentarem tais sistemas.

\section{ANÁLISE COMPARATIVA DA CONTRIBUIÇÃO DO SISTEMA}

No que tange à contribuição do sistema de controle interno municipal para o planejamento e gestão estratégica municipal e com base nas formas de contribuição quanto à contribuição dos controles legais PPA, LDO e LOA, do controle administrativo estratégico, e dos sistemas de informação e de indicadores estratégicos, criou-se um quadro comparativo da contribuição do sistema de controle interno municipal. Consideraram-se, para esta análise, as formas de contribuição citadas 2 vezes ou mais pelos gestores entrevistados, destacadas na Tabela 2.

Quanto à análise comparativa da contribuição do sistema de controle estratégico municipal para o planejamento e gestão estratégica municipal, foram citadas como formas de contribuição dos controles legais - PPA, LDO e LOA. Ao PPA, a revisão do planejamento, pois como instrumento orçamentário de planejamento possibilita definir quais os programas que serão trabalhados na gestão e o grau de consonância com os demais instrumentos de planejamento. inclusive porque hoje, na prefeitura, o PPA é o retrato do Plano de Governo; segundo, como exigência legal, obriga os gestores a organizar a gestão para que esteja em sintonia com aquilo que efetivamente havia sido proposto. Dessa forma, qualquer ação municipal somente poderá ser executada durante o ano (orçamento) se o programa estiver inserido no PPA (ANDRADE et al., 2005). 
Tabela 2 - Comparativo da contribuição do sistema de controle interno municipal

\begin{tabular}{|c|c|c|}
\hline $\begin{array}{lr}\text { Sistema } & \text { de } \\
\text { Controle } & \text { Interno } \\
\text { Municipal } & \end{array}$ & Formas de Contribuição & Frequência \\
\hline \multirow{9}{*}{$\begin{array}{l}\text { Contribuição dos } \\
\text { Controles Legais - } \\
\text { PPA, LDO e LOA }\end{array}$} & - integração das 3 leis & 11 \\
\hline & - parâmetro orçamentário de execução & 10 \\
\hline & - revisão do planejamento & 5 \\
\hline & - organização da gestão & 7 \\
\hline & $\begin{array}{l}\text { - planejamento orçamentário e financeiro do } \\
\text { próximo exercício }\end{array}$ & 6 \\
\hline & - consonância com o Plano de Governo & 4 \\
\hline & $\begin{array}{l}\text { - possibilidade de alteração para que fique dentro } \\
\text { do rumo }\end{array}$ & 4 \\
\hline & - priorização dos programas & 3 \\
\hline & - tomada de decisão & 3 \\
\hline \multirow{4}{*}{$\begin{array}{l}\text { Contribuição } \\
\text { Controle } \\
\text { Administrativo } \\
\text { Estratégico }\end{array}$} & - atualização do plano & 4 \\
\hline & - revisão do planejamento & 3 \\
\hline & - retroalimentação das informações estratégicas & 3 \\
\hline & - melhoria na tomada de decisão & 2 \\
\hline \multirow{4}{*}{$\begin{array}{l}\text { Contribuição } \\
\text { Sistema } \\
\text { Informação } \\
\text { Estratégico }\end{array}$} & - realimentação do planejamento & 7 \\
\hline & $\begin{array}{l}\text { - análise estratégica da gestão para a tomada de } \\
\text { decisão }\end{array}$ & 5 \\
\hline & - priorização das ações a serem trabalhadas & 2 \\
\hline & - redução do processo de trabalho. & 2 \\
\hline \multirow{7}{*}{$\begin{array}{l}\text { Contribuição } \\
\text { Sistema } \\
\text { Indicadores } \\
\text { estratégico }\end{array}$} & - norteia o rumo da gestão & 5 \\
\hline & - maior preocupação com a gestão para resultados & 4 \\
\hline & - melhoria na qualidade da informação da gestão & 4 \\
\hline & - maior preocupação com os resultados & 3 \\
\hline & - integração com o planejamento & 2 \\
\hline & $\begin{array}{l}\text { - correlação com os indicadores dos controles } \\
\text { legais }\end{array}$ & 2 \\
\hline & - organização da série histórica & 2 \\
\hline
\end{tabular}

Fonte: os autores.

Para a LDO, a maior frequência foi atribuída ao parâmetro orçamentário de execução, pelo fato de ser uma lei de diretriz com possibilidade de visualização e revisão orçamentária, ou seja, permite uma visão completa da real situação das finanças públicas (BRUNO, 2007).

Para a LOA, verificou-se a incidência de maiores frequências: o planejamento financeiro e orçamentário do próximo exercício; a integração com o PPA e LDO; e, a organização da gestão. Reiterou-se o fato da LOA ser um instrumento anual efetivo para a realização do PPA e LDO passível de monitoramento e avaliação das ações, e redefinição de rumo para o próximo exercício. O que explicita a política econômica e financeira e o programa de trabalho do governo municipal (REZENDE; CASTOR, 2006).

Quanto às formas de contribuição do controle administrativo estratégico para o planejamento e gestão estratégica municipal, destacaram-se: a atualização do plano; revisão do planejamento; retroalimentação das informações estratégicas; e alinhamento com os controles legais, fato atribuído à permanente revisão do processo de planejamento, alinhado à integração das 3 peças orçamentárias. Dessa forma, contribuem para que os objetivos da organização pública sejam alcançados e que as ações sejam conduzidas de forma econômica, eficiente e eficaz (CASTRO, 2008). Considerou-se a permanente preocupação da gestão para 
que se faça aquilo que realmente foi planejado, associado à melhoria na tomada de decisão para definição de diretrizes, priorização de metas, recursos e prazos das ações.

Para as formas de contribuição do sistema de informação estratégico para o planejamento e gestão estratégica municipal, foram citadas: realimentação do planejamento; análise estratégica da gestão para tomada de decisão; priorização das ações a serem trabalhadas e redução do processo de trabalho.

Atribuiu-se a estas formas de contribuição a importância de o sistema fornecer informações consistentes, atualizadas e em tempo real quanto ao rumo da gestão, ou seja, existe hoje na prefeitura, uma intenção para que sejam trabalhadas somente informações estratégicas capazes de possibilitar análise efetiva do que foi realizado e facilitar a tomada de decisão mais segura na definição de novas ações e encaminhamentos. Sobretudo, contemplam o processamento de grupos de dados das atividades operacionais e transações gerenciais que interagem entre si, transformando-os em informações estratégicas, visando o processo de decisão da alta administração (STAIR; REYNOLDS, 2002; REZENDE, 2008). Outro destaque foram os serviços ofertados no site da prefeitura, que contribuem na redução dos processos de trabalho.

E finalmente, quanto às formas de contribuição do sistema de indicadores estratégico para o planejamento e gestão estratégica municipal, houve destaque: norte do rumo da gestão; maior preocupação com a gestão para resultados; melhoria na qualidade da informação da gestão; correlação com os indicadores dos controles legais; organização da série histórica; e avanço no processo de monitoramento e avaliação.

Atribuiu-se a estas formas, a importância do sistema de indicadores estratégicos em contribuir na melhoria qualitativa da gestão com estabelecimento de controles efetivos capazes de possibilitar monitoramento e avaliação pela utilização de indicadores consolidados e de fácil leitura, bem como a preocupação da prefeitura com a profissionalização de seus gestores em atingirem melhores resultados. Sua maior contribuição é quanto à interpretação dos resultados, capaz de fornecer subsídios para a medição, padronização, acompanhamento e avaliação das ações municipais no processo de tomada de decisão (REZENDE; CASTOR, 2006; MARTINS; MARINI, 2010).

Identificou-se que, anteriormente, os gestores na maioria das vezes, trabalhavam com indicadores finalísticos; com a recente instituição de indicadores do programa Bom Governo, que estabelece indicadores de qualidade de gestão, passou-se a exigir maior profissionalização dos gestores para obrem resultados consolidados, ou seja, conscientizar os gestores em trabalhar a qualidade das informações para que possa melhorar a qualidade da gestão. 


\section{CONCLUSÃO}

A gestão pública municipal tem enfrentado vários desafios que sinalizam, para seus gestores, a necessidade de aperfeiçoar os meios de controlar e integrar ações de governo de forma efetiva para que os resultados de suas ações sejam alcançados, sejam resultados financeiros ou sociais.

É inegável a possibilidade da contribuição do sistema de controle interno municipal no auxílio aos gestores municipais quanto à verificação, análise e avaliação de seus resultados. Os controles legais e estratégicos apresentam-se no sentido de tentar garantir que a gestão pública se realize de forma planejada, integrada e transparente visando a efetividade da gestão e a melhor utilização do dinheiro público. Tais competências podem ser traduzidas em atividades de planejamento e gestão estratégica municipal para conduzir o município com o efetivo apoio dos seus gestores no controle da gestão. O uso de informações consistentes pode subsidiar a decisão, os controles e a gestão estratégica, contemplando inclusive as decisões nas temáticas sociais do município. Essas atividades podem ser facilitadas pela utilização dos sistemas de informação e indicadores estratégicos que, integrados à prática do planejamento e gestão municipal visam facilitar a tomada de decisão na correção das possíveis distorções de gestão. É indispensável que a gestão municipal prossiga em seus esforços de implementar e integrar esses sistemas para apoiar, realinhar e viabilizar o planejamento e gestão estratégica municipal. Com isso, pode-se melhorar a qualidade das decisões e, consequentemente, o desempenho da gestão pública municipal.

Portanto, pode-se presumir que os diferentes órgãos da prefeitura buscam um sistema integrado de controle interno que atue com efetividade, privilegiando os efeitos preventivos do controle bem como possam contribuir para o planejamento e gestão estratégica municipal.

Questões sobre a efetividade do sistema de controle interno e contribuições para o planejamento e gestão estratégica municipal foram observadas, tais como: a obrigatoriedade do cumprimento das leis que apesar de facilitar a integração no mesmo nível de detalhamento entre as três peças orçamentárias podem engessar o planejamento de longo prazo; a existência de controles administrativos na forma de contratos de gestão que são apoiados, monitorados e avaliados pela Unidade de Gestão do Plano de Governo sugere um avanço da gestão; a questionável necessidade do sistema de informação estratégica fornecer informações mais integradas e agrupadas para os tomadores de decisões; e o reconhecimento da importância da escolha de indicadores equilibrados e viáveis estarem sendo integrados aos instrumentos de controle estratégico da prefeitura. Também exige reflexão a dissonância entre os percentuais atribuídos pelos gestores entrevistados nas questões relacionadas aos sistemas de informação e de indicadores estratégicos atribuídas ao número reduzido de informações ou de indicadores estratégicos para fins de apoio às decisões dos gestores municipais. Aferiu-se também que a efetividade do sistema de controle interno na prefeitura e sua integração com o planejamento e gestão estratégica municipal ainda não é total, mesmo considerando as diferentes formas de contribuição ao planejamento e gestão identificadas nas análises elaboradas.

Essas análises dizem respeito às questões técnicas quantitativas e qualitativas que permitem observar o esforço da atual gestão em alinhar o planejamento à gestão para obtenção de resultados mais efetivos. Do ponto de vista qualitativo da pesquisa, observou-se a partir das entrevistas que o controle legal - PPA ao atender às exigências do Tribunal de Contas de Estado (TCE) em estabelecer o mesmo nível de detalhamento para as três peças orçamentárias em consonância com o Plano de Governo descaracterizou o PPA que vinha sendo utilizado na Prefeitura como instrumento de investimento de longo prazo. Por outro lado, esta mesma exigência legal, obrigou os gestores a organizar a gestão para que estivesse em sintonia com aquilo que havia sido proposto. A conseqüência culmina sobre a efetividade do instrumento, pois com a dependência de várias leis complementares para que estejam em consonância com as demais peças orçamentárias, para alguns gestores entrevistados ainda é percebida como 
retrabalho, mesmo sendo identificadas formas de contribuição para o planejamento e gestão estratégica municipal.

O controle legal - LDO, como parâmetro orçamentário de execução, possibilita à PMC uma reflexão do orçamento, visualização do valor orçado e permite flexibilidade na revisão do orçamento para que esteja em consonância com o PPA e LOA. Apesar de ser considerado estritamente técnico e de difícil entendimento, foram identificadas formas de contribuição e diagnosticada a efetividade do controle para a maioria dos gestores entrevistados. O controle legal - LOA, por ser uma lei autorizativa de execução e estar integrado com as demais leis orçamentárias e em consonância com o Plano de Governo e Plano Diretor da Cidade, além de ser um desdobramento do planejamento, permite flexibilidade no remanejamento das ações planejadas para acomodações emergenciais atribuídas às necessidades da população e ao interesse da gestão. Porém, na opinião de alguns dos gestores entrevistados, o limite de $20 \%$ de alterações, estipulado pela prefeitura para os diversos órgãos, compromete aquilo que foi planejado anteriormente, o que interferiu na efetividade do controle. O controle administrativo estratégico, hoje materializado pelos contratos de gestão firmados entre o prefeito com os dirigentes dos órgãos e apoiados, monitorados e avaliados pela Unidade de Gestão do Plano de Governo, tem facilitado a gestão e contribuído na melhoria da tomada de decisão dos gestores quanto à readequação de diretrizes, priorização de metas, recursos e prazos das ações, o que impacta transparência dos resultados alcançados. Muito embora a implantação deste controle seja ainda recente na Prefeitura, é visível sua efetividade e contribuição para o planejamento e gestão estratégica municipal.

Quanto ao sistema de informação estratégico, percebeu-se que os sistemas de informação utilizados podem permitir a otimização interna das informações. Observou-se que existe hoje, na prefeitura, uma intenção para que sejam trabalhadas somente informações estratégicas capazes de possibilitar análise efetiva do que foi realizado e facilitar a tomada de decisão mais segura para os gestores na definição de novas ações e encaminhamentos. Para tanto, coube aos gestores a conscientização e responsabilidade em alimentar tais informações nos sistemas. Ainda é um processo que demanda capacitação, acompanhamento e avaliação dos gestores públicos para que haja disponibilização compartilhada de informações mais ágeis e efetivas. Quanto ao sistema de indicadores estratégico, observou-se que o PLANGOV, foi construído concomitantemente com o Plano de Governo 2009-2012 e com os planos de ação dos órgãos, por ser relativamente recente está sendo aperfeiçoado e novos indicadores estão sendo construídos. Existe um esforço da alta administração no alinhamento dos controles legais e administrativos aos sistemas de informação e de indicadores para que possibilitem aos gestores municipais o alcance de resultados mais efetivos.

De maneira geral, os resultados aferidos demonstraram que a efetividade do sistema de controle interno municipal cabe à responsabilidade dos gestores no tratamento e disponibilização de informações estratégicas em tempo hábil, atribuída à melhoria da qualidade da informação e da gestão para o alcance de seus resultados.

A conclusão reitera que o sistema de controle interno integrado à prática do planejamento no município pode corrigir distorções de gestão. Para tanto, é essencial que as informações disponibilizadas sejam efetivas e integradas entre os diferentes órgãos para assegurar a viabilização de estratégias propostas, objetivos a serem atingidos e ações a serem trabalhadas. No que tange às contribuições do trabalho, elas estão direcionadas para a academia, para os gestores municipais que participaram da pesquisa e para outras prefeituras. Para a academia destacam-se as análises quantitativas e qualitativas realizadas que podem motivar estudos posteriores e aprofundamentos teóricos complementares que se constituem num amplo caminho a ser percorrido mais bem explorado pela academia. Para a prefeitura pesquisada, o trabalho pode contribuir com a descrição das relações entre os instrumentos de controle interno estratégico e suas contribuições para o planejamento e gestão, permitindo um entendimento mais abrangente sobre essas questões. $\mathrm{O}$ estudo de caso também pode facilitar 
outras pesquisas aplicadas em prefeituras para entender e sugerir alternativas para seus desafios emergentes de planejamento, execução, acompanhamento e controle de gestão.

Algumas limitações foram observadas sem comprometimento para a pesquisa. O método escolhido não se restringe a análises estatísticas, mas pela possibilidade de intensas análises qualitativas pode ocorrer generalização de resultados. O estudo de caso por ter sido caso único, impossibilita a análise comparativa entre prefeituras de outros municípios em virtude da realidade específica pesquisada. A pesquisa foi realizada em agosto de 2010 e o acompanhamento longitudinal não pode ser verificado, ou seja, não houve acompanhamento dos resultados. Quanto à quantidade e escolha das variáveis não foram atribuídas a nenhum modelo específico da literatura ficaram restritas ao interesse da pesquisadora em aprofundar seu conhecimento no tema da pesquisa. Outro aspecto limitador é atribuído à documentação das respostas fornecidas e não efetivamente o que os entrevistados deveriam ter respondido. A partir desse estudo, novas pesquisas poderão ser elaboradas utilizando-se outros métodos, amostras e por último, incluir a visão do cidadão frente a participação ou não nos controles.

Finalizando, observou-se que, apesar das dificuldades levantadas pelos gestores participantes, são os fatores humanos e sociais que de fato favorecem a efetividade e viabilizam as contribuições do sistema de controle interno municipal para o planejamento e gestão da prefeitura. 


\section{REFERÊNCIAS}

ANDRADE, N. A.; et al. Planejamento governamental para municípios: plano plurianual, lei de diretrizes orçamentárias e lei orçamentária anual. São Paulo: Atlas, 2005. 424 p.

ARAÚJO, I. P. S.; ARRUDA, D. G.; BARRETTO, P. H. T. Auditoria contábil: enfoque teórico, normativo e prático. São Paulo: Saraiva, 2008.366 p.

ATTIE, W. Auditoria: conceitos e aplicações. 3 ed. São Paulo: Atlas, 1998.

BRASIL. Lei Complementar n. 101, de 04 de maio de 2000. Estabelece normas de finanças públicas voltadas para a responsabilidade da gestão fiscal e dá outras providências.

BRUNO, R. M. Lei de Responsabilidade Fiscal e orçamento público municipal. 2 ed. rev. e atual. Curitiba: Juruá, 2007.

CASTRO, D. P. Auditoria e controle interno na administração pública: evolução do controle interno no Brasil: do Código de Contabilidade de 1922 até a criação da CGU em 2003. São Paulo: Atlas, 2008.

CAVALHEIRO, J. B.; FLORES, P. C. A organização do sistema de controle interno municipal. 4 ed. Porto Alegre: Conselho Regional de Contabilidade do Rio Grande do Sul, 2007.

CERTO, S; PETER, P. Administração estratégica: planejamento e implantação da estratégia. São Paulo: Makron Books, 1993.

CURITIBA. Decreto municipal n. ${ }^{\circ}$ 1.690, de 29 de dezembro de 2009. Aprova o Quadro de Detalhamento da Despesa para o exercício de 2010 e dá outras providências.

CURITIBA. Instituto de Pesquisa e Planejamento Urbano de Curitiba - IPPUC. Curitiba em dados.

CURITIBA. Lei n. ${ }^{\circ}$ 13.243, de 07 de julho de 2009. Dispõe sobre as diretrizes para a elaboração da Lei Orçamentária Anual para 2010 e dá outras providências.

CURITIBA. Lei n. ${ }^{\circ}$ 13.378, de 11 de dezembro de 2009. Dispõe sobre o Plano Plurianual para o período de 2010/2013.

CURITIBA. Lei n. ${ }^{\circ}$ 13.408, de 29 de dezembro de 2009. Estima a Receita e fixa a Despesa do Município de Curitiba para o exercício financeiro de 2010.

FREITAS, H.; BECKER, J. L.; KLADIS, C. M.; HOPEN, N.. Informação e decisão: sistemas de apoio e impacto. Porto Alegre: ORTIZ, 1997.

FURLAN, J. D.; IVO, I. M.; AMARAL, F. P. Sistema de informação executiva (EIS). São Paulo: Makron Books, 1994.

GIL, A. C. Como elaborar projetos de pesquisa. 4 ed. São Paulo: Atlas, 2002.

GRAHAM JÚNIOR, C. B.; HAYS, S. W. Para administrar a organização pública. Rio de Janeiro: Jorge Zahar Editora, 1994.

LOPES, R. P. P. A cidade intencional: o planejamento estratégico das cidades. Rio de Janeiro: Mauad, 1998.

MARTINS, H. F.; MARINI, C. Um guia de governança para resultados na administração pública. Publix Editora, 2010.

MATIAS-PEREIRA, J. Manual de gestão pública contemporânea. São Paulo: Atlas, 2007. 
MOTTA, P. R. Gestão Estratégica. In: VERGARA, S. C.; CORRÊA, V. L. A. (Org.). Propostas para uma gestão pública municipal efetiva. 2 ed. Rio de Janeiro: FGV, 2004.

PACHECO, R. S. Administração pública gerencial: desafios e oportunidades para os municípios brasileiros. In: Fundação Prefeito Faria Lima - Cepam. O município no século XXI: cenários e perspectivas. São Paulo: Cepam, 1999.

PEROTTONI, R.; et al. Sistemas de informações: um estudo comparativo das características tradicionais às atuais. Porto Alegre/RS: ReAd, PPGA/EA/UFRGS, v.7, n. 3, 2001.

PESSINI JÚNIOR, A. R. A estimativa do impacto orçamentário-financeiro das ações governamentais da Lei de Responsabilidade Fiscal. In: Boletim de Direito Administrativo n.10 e n.11 - out./nov. 2007. Editora NDJ, p. 1160- 1173 e 1249-1272.

PFEIFFER, P. Planejamento estratégico municipal no Brasil: uma nova abordagem. Brasília: ENAP, 2000. Texto para discussão, 37.

REZENDE, D. A. Planejamento estratégico público ou privado: guia para projetos em organizações de governo ou de negócios. São Paulo: Atlas, 2011.

REZENDE, D. A. Sistemas de informações organizacionais: guia prático para projetos em cursos de administração, contabilidade e informática. 3 ed. São Paulo: Atlas, 2008.

REZENDE, D. A.; CASTOR, B. V. J. Planejamento estratégico municipal: empreendedorismo nas cidades, prefeituras e organizações públicas. 2 ed. Rio de Janeiro: Brasport, 2006.

RODRIGUEZ, M. V. Gestão do conhecimento: reinventando a empresa para uma sociedade em valores intangíveis. Rio de Janeiro: IBPI Press, 2001.

ROESCHE, S. M. A. Projetos de estágio e de pesquisa em administração: guia para estágios, trabalhos de conclusão, dissertações e estudos de casos. 2 ed. São Paulo: Atlas, 1999.

ROSSI, L. C.; et al. Gestão pública municipal: idéias e práticas para prefeitos, gestores e técnicos. Mato Grosso do Sul: Letra Livre, 2004.

SANTOS, C. S.. Introdução à gestão pública. São Paulo: Saraiva, 2006.

SILVA, E. L.; MENEZES, E. M. Metodologia de pesquisa e elaboração de dissertação. 3 ed. Florianópolis: Laboratório de Ensino a Distância da Universidade Federal de Santa Catarina, 2001.

SILVA, M. M.; AMORIM, F. A.; SILVA, V. L. Lei de Responsabilidade Fiscal para os municípios: uma abordagem prática. São Paulo: Atlas, 2004.

STAIR, R. M.; REYNOLDS, G. W. Princípios de sistemas de informação: uma abordagem gerencial. 4 ed. Rio de Janeiro: Livros Técnicos e Científicos Editora, 2002.

VAINER, A.; ALBUQUERQUE, J.; GARSON, S. Manual de elaboração: o passo-a-passo da elaboração do PPA para municípios. 2 ed. Brasília: Ministério do Planejamento, Orçamento e Gestão/Banco Nacional de Desenvolvimento Econômico e Social, 2005.

YIN, R. K. Estudo de Caso: planejamento e métodos. 2 ed. Porto Alegre: Bookman, 2001. 